\title{
Putting Theory of Change into Use in Complex \\ Settings
}

\author{
Boru Douthwaite \\ Selkie Consulting Ltd. \\ Farid Ahmad \\ ICIMOD \\ Ghulam-Muhammad Shah \\ ICIMOD
}

\begin{abstract}
This paper argues that theory of change can be used to help stakeholders in agricultural research for development projects collectively agree on problems and visions of success. This helps them feel greater ownership for their project, motivation to achieve outcomes, and understanding of how to do so. However, the dynamic is damaged if projects are pushed to be too specific too early about the outcomes for which they are to be held accountable. This is most likely to happen when system response to project intervention is uncertain, as opposed to projects that work with existing pathways and partnerships where the role of research is well established.
\end{abstract}

Keywords: accountability, adaptive management, impact pathways, learning, participation, results-based management

Résumé : Le présent article fait valoir que la théorie du changement peut aider les parties prenantes dans le domaine de la recherche agricole axée sur des projets de développement à s'entendre collectivement sur les problèmes et sur l'aspect que prendra la réussite. Cela les aiderait à se sentir plus responsables de leur projet, motivés à atteindre les résultats et confiants dans la façon d'y arriver. Cependant, la dynamique peut être perturbée si on s'attend à ce que les résultats d'un projet soient précisés trop tôt. Cela risque d'arriver plus fréquemment lorsque la réponse d’un système à l'intervention dans un projet est incertaine, par opposition aux projets qui font appel à des cheminements et à des partenariats existants, où le rôle de la recherche est bien établi.

Mots clés : responsabilité, gestion adaptive, cheminements d'impact, apprentissage, participation, gestion axée sur les résultats

There is increasing recognition that rural research and development (R\&D) programs intervene in complex systems (Patton, 2010; Stame, 2004). This is particularly true for agricultural research and development organizations, such as those

Corresponding author: Boru Douthwaite, Selkie Consulting Ltd., Kilmeena, Westport, Co. Mayo, F28W654, Ireland; bdouthwaite@gmail.com 
that form the CGIAR ${ }^{1}$ and AIRCA, ${ }^{2}$ because they work at different scales, from the community to the global level, with different types of stakeholders (Lilja, Kristjanson, \& Watts, 2010; Van Vianen, Reed, \& Sunderland, 2015), often on contested issues. The impact of agricultural $\mathrm{R} \& \mathrm{D}$ depends on interactions between stakeholders at different scales (Renkow \& Byerlee, 2010), which can be difficult to predict (Stame, 2004). At the same time, agricultural R\&D organizations are generally staffed by bio-physical researchers trained to study parts of systems rather than interactions (Douthwaite et al., 2017). Together, these factors make it difficult to plan, implement, and evaluate projects against initial promises. At the same time, complexity, with its assumption of non-linear effects, holds out the promise that small, intelligent interventions can "harvest complexity," that is, achieve a disproportionately large impact through catalyzing and supporting tipping points (Patton, 2010).

The authors of this paper have been involved in developing and using an approach to planning, monitoring, and evaluation that also seeks to harness complexity. The approach, first used in 2006, is called Participatory Impact Pathways Analysis (PIPA) (Douthwaite et al., 2007) and involves the participatory construction and revisiting of theory of change. Since then, PIPA has been used by several CGIAR and AIRCA centres. It has been adapted by the French agricultural R\&D organization CIRAD (Blundo Canto et al., 2018) and used as the core approach underpinning the University of Sussex's STEPS Centre's approach to impact (Ely \& Oxley, 2014). There have been at least 10 journal articles and book chapters published on PIPA and earlier work upon which it is based (Douthwaite, Kuby, Van De Fliert, \& Schulz, 2003).

This paper revisits our first PIPA article, published in this journal (Douthwaite et al., 2007) to explore if and how theory of change can be used by agricultural R\&D organizations to plan, monitor, and evaluate research while at the same time harnessing complexity. We do so by comparing and contrasting two applications of PIPA, which the authors led, to answer four learning questions:

1. What motivated the development, adaptation, and use of PIPA?

2. What worked well with PIPA, and why?

3. What did not work so well, and why?

4. What can we learn from PIPA about how to make the use of theory of change better able to harness complexity?

\section{CONCEPTS AND TERMS}

In this section, we define and explain the main concepts and terms used in the paper. According to the literature (e.g., Stein \& Valters, 2012), confusion over terminology is one of the barriers to the use of theory of change. Our unit of analysis is the project rather than a program. In the CGIAR and AIRCA centres, programs are normally constructed from a number of discrete projects that are expected to 
contribute to a common program goal. Still, nearly all of what is written about project theory of change also applies to programs.

\section{Program theory, impact pathway, outcome pathway, and theory of change}

We understand a project's "impact pathway" to be a synonym for a project's "program theory" (Douthwaite et al., 2003). A program theory is "a plausible and sensible model of how a program is supposed to work" (Bickman, 1987, p. 5). The model "specifies a chain of causal assumptions linking program resources, activities, intermediate outcomes and ultimate goals" (Wholey, 1987, p. 78).

We coined the term "outcome pathway" to describe how project intervention is expected to lead to immediate outcomes, that is, changes in behaviour and/or knowledge, attitude, and skills for a particular set of stakeholders. An outcome pathway is described in tabular form by an "outcome logic model." An impact pathway describes how a project's outcome pathways work together in a particular context to achieve intermediate outcomes and impact over a longer timeframe. It is expressed visually, normally with boxes and arrows and includes a narrative description of the causal assumptions implicit in the arrows.

Following Vogel (2012), we understand "theory of change" to be an umbrella term that can refer to any causal model that includes descriptions of the following four elements, also captured in a diagram and narrative:

- $\quad$ context and acknowledgement of existing change processes and actors able to influence change;

- the long-term change envisaged;

- the process and sequence of change; and

- $\quad$ assumptions on how change happens.

Theory of change, unlike program theory, does not necessarily apply to a project or a program. Theories of change can be overarching or detailed, with detailed ones nested under overarching ones (Mayne, 2015). At the upper limit of abstraction, theory of change can refer to the realist concept of middle range theory ${ }^{3}$ positioned between published social science theory and program theory (Pawson, 2013).

Theory of change models are nearly always used ex ante, in the sense that they are used to predict how change is expected to happen. However, they can also be used to explain how change has happened. A "theory of change" approach is a process that develops and uses a theory of change for planning, monitoring, and/or evaluation purposes.

A logical framework predates the use of theory of change in agricultural R\&D as a way of articulating a project's causal logic. Logical frameworks, or logframes as they are also called, assume a linear pathway (see Figure 1). They have been criticized for not showing the underlying causal mechanisms that lead to change, for being overly linear, for going too far into the future, and for taking a lot of time to complete (Dhillon \& Vaca, 2018). 


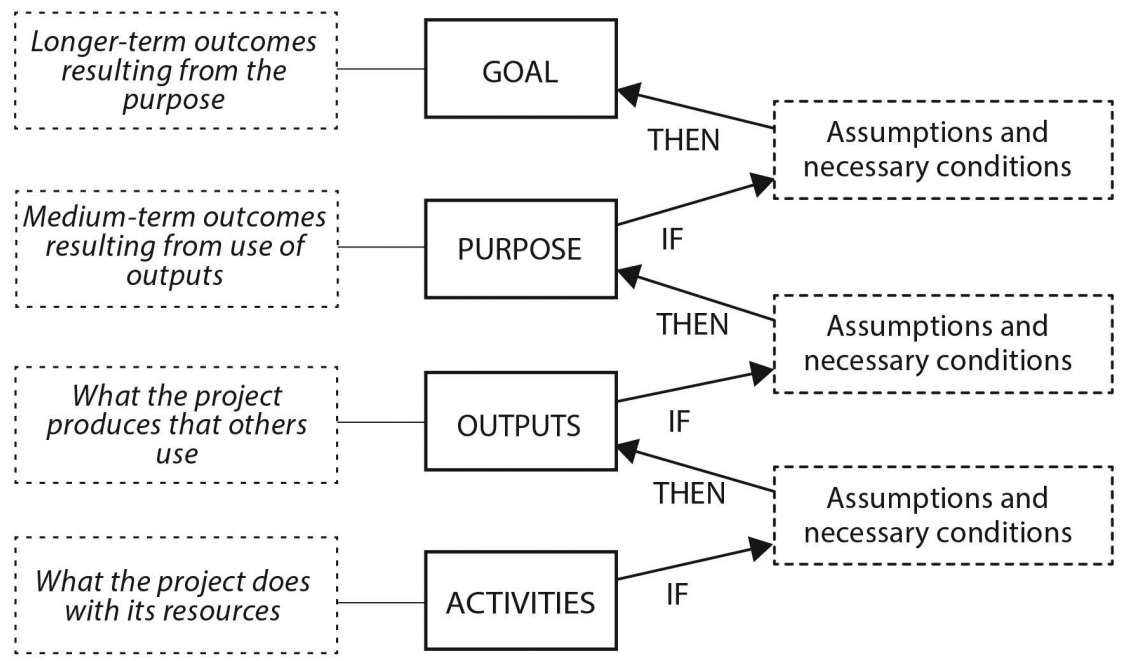

Figure 1. The causal steps of a logical framework (Douthwaite et al., 2007, p.132)

\section{Outcome trajectory}

An outcome trajectory is a causal model that describes how a project has contributed to a significant outcome, either expected or unexpected. It is an ex post use of theory of change and describe real causal pathways and outcomes rather than predicted ones.

\section{Complexity and emergence}

A complex system is one in which outcomes cannot be fully understood by studying its component parts (Gallagher, Appenzeller, \& Normile, 1999, p. 79) because of path dependency, interactions, feedback loops, and emergence. Path dependency is the tendency for past events to shape future outcomes through enduring norms and patterns of behaviour. Feedback loops can be self-reinforcing; for example, good reviews of a technology lead to more sales, leading to more reviews, and so on. They can also be negative, or dampening, for example, bad reviews leading to falling sales (Senge, 1990).

Emergence is characteristic of complex systems. Emergence is "the arising of novel and coherent structures, patterns and properties during the process of self-organization in complex systems" (Goldstein, 1999, p. 49).

\section{Harnessing complexity}

We understand harnessing complexity to be purposeful intervention in complex systems to lever a disproportionately large response through the use of system dynamics. One strategy for harnessing complexity assumed in this paper is to catalyze and/or identify emerging outcome trajectories and then work to stabilize and amplify them (Snowden, 2010). 


\section{METHODOLOGY}

Our methodology is action research in which we have reflected on our respective work to develop and adapt PIPA over a number of years, following Bradbury's (2015) definition of action research. ${ }^{4}$ We engaged in individual and collective reflection by constructing timelines of events in two case studies and then writing and agreeing upon narratives to describe them. The process of identifying, agreeing, ordering, and describing key events, and then agreeing why they were significant and linked, structured our reflection and analysis to answer the learning questions. Our method was guided by

- case-study methodology with respect to developing understanding from rich and detailed descriptions of events in context (Yin, 2013);

- the institutional history approach (Shambu Prasad, Hall, \& Laxmi, 2006) in terms of paying attention to the development and influence of norms and power;

- process tracing (Collier, 2011) with respect to understanding how and why key events unfolded as they did before establishing causal inferences between them; and

- Reason and Torbert's (2001) concepts of first- and second-person practice in terms of the authors carrying out individual reflection and analysis before carrying out collective analysis.

We compare and contrast two major efforts to introduce PIPA. The first case was the development, introduction, and use of PIPA in the CGIAR Challenge Program on Water and Food (CPWF) from 2005 to 2012, led by the first author. The second case is the introduction and use of PIPA by the International Centre for Integrated Mountain Development (ICIMOD) from 2012 to 2018, led by the second and third authors. ${ }^{5}$

We constructed the timelines and narratives in both cases by identifying events from memory and by going through relevant documentation and e-mail conversations since 2005. We also carried out two similar online surveys of how staff viewed PIPA in the CPWF and at ICIMOD.

\section{Case 1: Development and adoption of PIPA in the CPWF}

PIPA was developed by the Impact Group of the CGIAR Challenge Program on Water and Food (CPWF).

\section{Context}

The CPWF was a global agricultural R\&D program that funded over 80 projects in nine river basins in Africa, Asia, and Latin America over 10 years, starting in 2003. The CPWF developed PIPA in response to the increasing demand from CPWF donors to know the outcomes and impacts they could expect from their investments while at the same time being more effective in generating them in the first place. 


\section{Development and early adoption}

PIPA is based on participatory workshops. The first PIPA workshop was held in Ghana in January 2006 for the eight projects working within the Volta River basin. Two to three representatives attended from each project.

Day 1:Developing a cause-and-effect-logic. Participants develop a problem tree for their project that starts with the overarching problems that the project aims to address and finishes with the specific problems the project will work on. They then develop a vision of project success after the project has finished. Experience showed that when working on several projects from the same program, sharing problem trees and visions helped participants better understand each other's aims, a prerequisite for successful programmatic integration.

Day 2: Developing a network perspective. Problem trees are deceptively simple and can lure people into thinking that solving a limited set of discrete problems can begin a domino-like cascade that leads to impact. Day 2 balances cause-effect logic with a network perspective in which impact comes about as a result of interactions between actors in an innovation system. Participants draw a network map showing how actors key to the project are interacting with each other and their level of knowledge and attitude toward the project. Participants then identify necessary changes to these relationships and attitudes to achieve the vision identified during the previous day.

Day 3: Bringing the two perspectives together. Participants distil and integrate the cause-and-effect logic and network perspectives into an actor-oriented logical framework called an "outcome logic model" (Table 1) developed for PIPA. The model shows changes in actor knowledge, attitude, skills (KAS), and practice and the strategies the project will employ to make the changes happen. Each row reads from right to left, beginning with project strategies and ending with the change in actor practice or behaviour. Each row represents an "outcome pathway," that is, a pathway to an actor, or group of actors, doing something differently.

Participants then work to draft their project's impact pathway, which is a description of how the immediate outcomes described in the rows of the outcome logic model might work together to bring about intermediate outcomes and impact over a longer timeframe. Participants are told that the outcome logic

Table 1. Outcome logic model

\begin{tabular}{|c|c|c|c|}
\hline $\begin{array}{l}\text { Actor (or group } \\
\text { of actors who } \\
\text { are expected to } \\
\text { change in the } \\
\text { same way) }\end{array}$ & $\begin{array}{l}\text { The actor's change } \\
\text { in practice to } \\
\text { achieve the pro- } \\
\text { ject's vision }\end{array}$ & $\begin{array}{l}\text { Change } \mathrm{KAS}^{\mathrm{a}} \\
\text { required to } \\
\text { support the } \\
\text { change in } \\
\text { practice }\end{array}$ & $\begin{array}{c}\text { Project strategies } \\
\text { to bring about } \\
\text { changes in KAS } \\
\text { and practice }\end{array}$ \\
\hline
\end{tabular}

a Knowledge, attitude, and/or skills.

${ }^{b}$ Project strategies include developing project outputs with stakeholders, capacity building, communication, and political lobbying. 
model can be used to frame monitoring and evaluation, because each row of the model represents a change hypothesis for which targets can be set and indicators established and monitored. Finally, participants develop an action plan to further develop their outcome logic model, impact pathway, and M\&E system.

How PIPA workshop outputs were used differed from basin to basin. For example, participants at a follow-up workshop in Ghana in October 2006 identified three outcomes:

1. Becoming a program: Some participants in the Ghana PIPA workshop held a seminar to share PIPA tools with their colleagues, which helped them to see themselves as part of a program rather than a collection of projects.

2. Changing policy: The leader of a project on urban agriculture realized the importance of political lobbying at the PIPA workshop and as a result used an opportunity to make the case for the safe use of waste water for irrigation of crops at a key workshop organized by the Ministry of Food and Agriculture. His intervention helped reverse a ban on the use of waste water in urban agriculture in favour of a more holistic approach to managing health risks based on research results.

3. Method development: The PIPA workshop reminded a researcher of social network analysis, which she subsequently combined with power mapping to develop a new tool called "influence network mapping." The method has been subsequently renamed as "Net-Map," published, and widely adopted (Schiffer \& Hauck, 2010).

The CPWF Impact Team that developed PIPA published two journal articles (Alvarez et al., 2010; Douthwaite et al., 2007;), a book chapter (Douthwaite et al., 2009), a brief (Douthwaite, Alvarez, Thiele, \& Mackay, 2008), and a wiki (http:// pipamethodology.pbworks.com) to establish PIPA as an approach, share experience, and promote its use.

\section{Adaptation and wider use}

In 2006, the PIPA Team started receiving requests to apply PIPA in other projects and programs. PIPA was subsequently adopted by the CGIAR Andean Change Program and an EU-funded farm management program in Latin America. ${ }^{6}$ Both pushed the main PIPA architects to standardize the language and approach through the use of worksheets and clearer definitions.

The CPWF's second phase started in 2009. The first author became the Innovation and Impact Director, responsible for monitoring and evaluation.

The CPWF made it a requirement that each project develop an outcome logic model with its key partners. However, project staff started to complain when they realized that the CPWF, through the outcome logic model, was expecting them to take on some responsibility for producing outcomes, not just research outputs. Adding to their sense of unease was the fact that some of the outcome pathways proved to be rather aspirational and therefore hard to achieve in practice. In 
response, some projects had over-generalized with respect to target actors and had picked spurious indicators, for example, number of field trials as an indicator of influencing potential adopters. The underlying causal logic became obscured in detail and verbiage. The impact pathway narratives that were supposed to articulate how the individual outcome pathways work together to achieve scaling were weak. Another complaint was that the project reporting templates, and the language used to explain them, changed and were not always clear. Together, the complaints and concerns led to a sense of disillusionment with PIPA.

The pushback against PIPA came to a head during a program-wide meeting held in Lao PDR in January 2011. As a result, the CPWF Impact Team helped projects identify the two or three core outcome pathways in their outcome logic model for which they felt they could make meaningful progress toward outcomes. The program also changed the reporting format to put more emphasis on research results as compared to achieving outcomes.

The CPWF closed in 2013, without the hoped-for third phase. This meant that the simpler outcome logic models were never revisited to test the underlying causal theories from which they were constructed.

In August 2013, the CPWF carried out a survey of how Phase 2 project leaders and key staff viewed the use of outcome logic models and theory of change more generally. Half of the 60 staff responded. A quote from a project leader summarizes well a commonly held sentiment:

The CPWF experience has certainly moved my thinking on research for development/ outcome-based research. I was initially confused by the whole outcome logic model concept but I now strongly endorse the underlying thinking which is about making research relevant for development and using it to catalyze change. One of the unseen impacts of CPWF has been in the personal transformation of some, not all, scientists involved in the program. They can now see a clear link between the science they do and the changes in development practice that they aspire to.

What participants liked about PIPA and the use of outcome logic models were the following:

- the way of thinking it brought with the focus on actors and outcomes;

- clarification of the links and resources required for scaling;

- acknowledgement of influence and power in the scaling process;

- highlighting the role of communications; and

- helping build collective ownership of the project through joint planning.

What respondents thought did not work so well were these issues:

- the choice of outcome targets that became specific too soon and were overly ambitious;

- in prioritizing achievement of outcomes, PIPA squeezed out the planning and adaptation that also need to happen in research; 
- the amount of time and capacity to understand the concepts, particularly when they kept changing; and

- inflexibility in templates that were formulaic.

Overall, $80 \%$ of respondents thought that the CPWF's M\&E system was better than other M\&E systems they had worked with, suggesting that efforts to deal with the problems had been at least partially successful.

\section{Adoption of PIPA beyond the CPWF}

Use of PIPA increased after the closure of the CPWF. The first author used PIPA as part of stakeholder engagement in the CGIAR Research Program on Aquatic Agricultural Systems. PIPA was used in three other CGIAR research programs. It was adopted by ICIMOD, as the next case will describe. CIRAD, the French agricultural R\&D organization, adopted PIPA as the basis of its ex ante approach to impact assessment (Blundo Canto et al., 2018). PIPA was also adopted as the core method underpinning the University of Sussex's STEP Centre's approach to impact (Ely \& Oxley, 2014).

\section{Case 2: Adoption and use of PIPA by ICIMOD}

ICIMOD first used PIPA in 2012 as part of a long-running effort to develop and improve its planning, monitoring, and evaluation (PM\&E).

\section{Context}

ICIMOD is an intergovernmental knowledge and learning centre that develops and shares research, information, and innovations to empower people in the eight regional member countries-Afghanistan, Bangladesh, Bhutan, China, India, Myanmar, Nepal, and Pakistan. It provides a regional platform where experts, planners, policymakers, and practitioners can exchange ideas and perspectives to achieve sustainable mountain development. ICIMOD facilitates knowledge exchange across the region, helps customize international knowledge and tailors it to the region's needs, and brings regional issues to the global stage.

ICIMOD adopted PIPA in the context of an institute-wide move to use results-based management and a corresponding upgrading of its PM\&E system that began in 1998. The centre adopted PIPA to help bring about change in the face of complexity through real-time learning coupled with theory of change.

In 2008, ICIMOD started to report to its Board using a common set of indicators of change to which its projects were supposed to contribute. This expectation coincided with, and contributed to, a move toward a programmatic approach that favoured larger, more complex programs that worked on more of the links between program implementation and impact.

In 2010, an independent midterm review of ICIMOD's five-year plan recommended that its regular planning, monitoring, reporting, and evaluation system be used by all stakeholders and that credible impact pathways be identified for their projects. The problem was they were being asked to do so using logical frameworks that constrain the number of causal steps from implementation to 
impact to just four (see Figure 1). Logical frameworks are not good at showing the bespoke, actor-centric, and often multi-step causal pathways by which a particular project works with specific actors in a particular location to produce changes in behaviour that lead to impact (Douthwaite et al., 2007).

\section{Early adoption and use}

PIPA was first used at ICIMOD during the inception workshop of the Australianfunded Koshi Basin Initiative held in September 2012. Fifty participants attended from partner organizations in China, Nepal, India, and Bangladesh, and international and regional institutes, most of whom had been involved in developing the successful proposal. The project used PIPA in part because the new Director General hired at ICIMOD the previous year knew of the work on PIPA after having worked on CPWF projects in his previous job. The CPWF Impact Team gave virtual support to the first workshop, which resulted in important changes to the original project proposal, as it was the first time that staff and stakeholders had met together face-to-face to discuss what they wanted to do.

PIPA became a central part of ICIMOD's PM\&E system, and the SPM\&E Unit facilitated 13 PIPA workshops from 2013 to 2016. The Unit produced a workshop report including problem trees, network maps, and outcome logic used to develop the impact pathway. The centrepiece of the workshop report was a onepage schematic of the project impact pathway. Unlike the CPWF Impact Team, the SPM\&E unit recommended that ICIMOD projects use their impact pathways to develop a traditional logical framework as their main planning tool, rather than an outcome logic model.

Also, in 2013, the Unit developed a monitoring and evaluation strategy for ICIMOD that was approved by the ICIMOD Board in October of that year. The document specified that all new projects should have a six-month inception period to allow for a PIPA workshop prior to finalizing action plans that staff and stakeholders should attend.

\section{Revisiting impact pathways}

In 2016, the SPM\&E unit commissioned a formative review of their work on PIPA, carried out by the first author. The work involved an online survey similar to the CPWF one (20 out of 62 staff responded), a reflection on the use of impact pathways attended by 30 staff, key informant interviews, and a review of impact pathways developed by ICMOD projects.

The review found that what respondents liked about PIPA and the use of impact pathways were the following:

- the way of thinking that it brings about impact;

- the participatory process to develop impact pathways with stakeholders that gives purpose;

- clarifying the output to immediate outcome linkages;

- the fact that it reminds one of deliverables;

- clarification of strategy; 
- the bringing in of risks and assumptions; and

- the fact that it is not necessarily linear.

Respondents' main suggestions for improvements were as follows:

- make the process of developing impact pathways simpler and more pragmatic;

- $\quad$ guard against the impact pathway diagrams being overly simplistic;

- better manage the level of detail that it is possible to get caught up in;

- do not try to plan what cannot be planned;

- $\quad$ question the usefulness of planning beyond immediate outcomes in short duration projects;

- $\quad$ provide more worked examples of impact pathways to support people climbing the steep learning curve

- $\quad$ keeping the impact pathways alive after the workshop by revisiting them;

- improve understanding and choice of indicators to use at different stages of result chain;

- $\quad$ suggest better ways to deal with risks and assumptions; and

- be clearer on the link between the impact pathways, Regional Program log-frames, and the budgeting process.

The survey found that $75 \%$ of respondents thought that the ICIMOD PM\&E system was better than others they had encountered.

The formative review found that, as with the CPWF, the impact pathways identified during project inception encompassed a broader set of changes over a longer timeframe than a project could reasonably expect to achieve by itself. The review also found that the logical frameworks focused on producing outputs and were missing clear causal assumptions that linked outputs to outcomes achieved by actors.

In response, the authors developed an ex post approach to revisiting impact pathways, consisting of five steps:

1. Identify the changes to which the program is contributing by bringing implementers together and asking them. This can also be done by using an approach such as Most Significant Change (Davies \& Dart, 2005) or Outcome Harvesting (Wilson-Grau \& Britt, 2012).

2. Create a timeline to identify the ex post outcome trajectories through which the program has contributed to the changes identified in step 1. Write out a narrative that explains the contribution and look for gaps in the logic.

3. Map outcome trajectories into the future to predict future outcomes and impacts, and identify milestones, indicators, and targets for them.

4. Modify the overarching impact pathway, logical framework, and action plans based on steps 2 and 3 .

5. Monitor progress against indicators and periodically repeat the process. 
We used the approach with seven projects and went the furthest with the Himalayan Adaptation, Water and Resilience (HI-AWARE) Initiative, which revisited its impact pathway as part of a midterm review in 2016. Staff and partners identified 12 outcome trajectories to which the project had contributed during two-and-ahalf years of implementation. For example, HI-AWARE influenced the decision by the Government of Bihar to support the use of Eco-San toilets in flood-affected areas and provided data used in the formulation of the Nepali Adaptation Plan. HI-AWARE has subsequently changed its logical framework and plan to support and amplify these trajectories. None was specifically envisioned in the original impact pathway, but all can be nested within it. The specificity and detail in the pathways allowed for the identification of more realistic and testable outcome indicators and targets for M\&E.

\section{Future prospects}

ICIMOD's current five-year plan (ICIMOD, 2017, pp. 23-24) commits the Centre to the continued use of PIPA across its projects and programs until 2022. The Plan says that the Centre is using PIPA because of the highly non-linear nature of the change to which it wishes to contribute. The document says that PIPA helps provide "a common understanding among stakeholders about what defines success and what it takes to get there; a powerful communication tool that captures the complexity of the project or program; and, a clear and testable hypothesis about how change will occur" (p. 23).

\section{DISCUSSION}

The objective of this paper was to explore if and how theory of change can be used by agricultural $\mathrm{R} \& \mathrm{D}$ organizations to plan, monitor, and evaluate research while at the same time harnessing complexity. In this section we compare and contrast the two case studies to address this question by answering four learning questions.

\section{What was the motivation to develop and use PIPA?}

The case studies show that the development and use of PIPA was driven in both institutions by an internally generated desire to better link research to outcomes and to harness complexity, as well as the need to demonstrate to donors how planned and ongoing projects will lead to impact. Both institutions were being asked to strengthen their PM\&E systems and to change their normal work practices to better achieve change, and to better monitor and evaluate their attempts to do so. Both institutions wanted project partners to be involved in PM\&E. The use of PIPA was pushed by champions in both organizations and also received support from senior management and their respective boards.

\section{What worked well?}

PIPA allowed project staff and partners to identify and agree on actor-centric pathways in which any number of causal steps can be used to link project activity to eventual impact. Participants found that the collective process of doing this 
helped them feel greater ownership for, and motivation to implement, their respective projects. It also helped change their thinking about impact and become more accepting of a results-oriented way of working, as shown in two surveys.

ICIMOD developed an approach to revisiting impact pathways based on identifying the ex post outcome trajectories to which the project is contributing. This helped staff identify how they could harness complexity through identifying and reinforcing outcome trajectories.

There is some evidence that participation in PIPA workshops led to outcomes. In the Volta Basin, these included a self-organized sharing of concepts and strengthening of a sense of being a program, the seizing of an opportunity to influence policy with respect to use of waste water in urban agriculture, and a methodological breakthrough that led to a published and widely used tool for understanding and visualizing stakeholder goals in multi-stakeholder organizations.

\section{What did not work so well?}

In both cases, PIPA produced impact pathways that were overly ambitious and general for the respective projects to use for action planning and identification of outcome indicators, without further clarifying the causal logic after the workshop. In the CPWF, workshop participants built an impact pathway for their project from an average of five or six outcome pathways. Project staff subsequently struggled to derive specific plans and sensible indicators until they had been able to identify two or three outcome pathways where the project could expect to make the greatest contribution. This often required some time for the system to react to project intervention.

Project leaders in the CPWF complained that outcome logic models put too much emphasis on the links between outputs and outcomes and that this was to the detriment of planning and monitoring the research required to develop the outputs in the first place. ICIMOD partly addressed the issue by using the traditional logical framework instead of outcome logic models as the main planning tool. ICIMOD dealt with the risk that logical frameworks lose the connection to their broader impact pathways by developing an approach to revisiting project impact pathways mid-term. The approach reasserts causal logic based on what has started to happen and modifies the logical frameworks accordingly.

Another complaint was that users found the concepts and language confusing, in part because they changed over time. For example, CPWF talked about "impact pathways and theories of change" without being clear on the difference between them. We found that some staff wanted very well-defined templates to fill in and precise definitions, while others complained that templates were too rigid and were happy with some ambiguity and overlap in the meaning of terms.

\section{What can be learned about using theory of change to harness complexity and to better help planning and M\&E?}

Both cases suggest that PIPA was successful in making the use of theory of change more complexity-aware. Through the idea of pathways and the use of network 
maps, PIPA provided metaphors to think about how R\&D projects can influence change in rural innovation systems. Network mapping helped participants discuss and visualize interactions between actors, who has power in the network, and who may be supportive or not of what their project wants to do. Combining network maps helped show CPWF brokerage at basin and global scale, which helped give a qualitative sense of the potential impact of the CPWF.

We found that key to revisiting theory of change is distinguishing between ex ante outcome pathways that predict what is likely to happen and ex post outcome trajectories that model what has happened. When intervening in complex systems, emergence and feedback loops mean that outcome trajectories can be different from predicted outcome pathways. ICIMOD's approach to revisiting theory of change builds outcome pathways that are extrapolations of outcome trajectories, in other words, describing outcome pathways that use history (i.e., path dependency) to increase their predictive power.

In projects working to catalyze and develop new outcome trajectories, it makes sense to wait for them to emerge before committing to specific outcome indicators and targets. However, projects working in an existing, well-established outcome trajectory can confidently commit to specific outcome indicators and targets from the start. Conventional project timeframes and PM\&E approaches will work for them.

Revisiting theory of change is key to harnessing complexity because it allows for the early identification of outcome trajectories to which the project is contributing, which if stabilized and amplified can lever large-scale change. ICIMOD's five-step approach successfully identified outcome trajectories that could not have been predicted at the start. The outcome trajectories added detail to the original project impact pathway without contradicting it-they helped identify, flesh out, and understand real underlying processes and mechanisms with the potential to achieve the type of change envisioned in the original impact pathway. Revisiting theory of change led to changes to action plans, logical frameworks, and performance indicators.

Finally, some ambiguity over concepts, terms, and what exactly PIPA is and is not was a constant feature in both cases. Patton (2010, p. 12) finds that developmental evaluators who engage in complex systems need "to be agile, open, interactive, flexible, observant, and highly tolerant of ambiguity." Hence it may well be that some level of flexibility and ambiguity with regard to PIPA and other approaches to engaging in complex systems is a good thing, and practitioners should learn to live with it rather than remove it.

\section{CONCLUSIONS, INSIGHT, AND AREAS OF FUTURE WORK}

The paper has shown that the participatory use of theory of change can help harness complexity as well as support planning and M\&E, with some caveats. PIPA worked best in creating an appreciative space in which staff and stakeholders could agree on a common vision for their project, the overarching pathways to achieve it, and their respective contributions within them. This helped motivate 
action and build trust. PIPA also provided complexity-aware metaphors (pathways and networks) to help participants think about how project intervention might contribute to change.

Key to the successful use of theory of change is to differentiate between ex ante outcome pathways that predict future project outcomes and ex post outcome trajectories that model how outcomes have been achieved. Ideally, projects should work with outcome pathways that build on outcome trajectories; in other words, projects should work within processes and patterns of behaviour already in place. Only then can they commit to specific outcome targets and indicators with any degree of confidence in achieving them. Some projects, such as those working on plant breeding, are embedded in well-established outcome trajectories from the start. Other types of project, such as those that work on natural resource management issues with multiple partners, need to first establish and strengthen emergent outcome trajectories with which to engage. Such projects require an inception phase before their theory of change can become specific enough to be used for monitoring and evaluation for accountability purposes.

In our experience, while some projects may be able to negotiate a six-month or one-year inception phase, very few are given an open-ended formative phase to properly explore, establish, and describe new outcome trajectories. We suspect that a number of projects are pushed to appear more certain about likely impact than is reasonable and make commitments they struggle to keep. Implementation becomes the pursuit of spurious targets along fictional pathways, rather than the identification and nurturing of emerging trajectories that could deliver beneficial change, as complexity science suggests. This tentative conclusion requires further validation. If upheld, it has major implications for how R\&D programs are planned and funded, in particular those that aim to engage the poor, vulnerable, and marginalized who are not well embedded in existing outcome trajectories.

A second insight is that a certain degree of ambiguity existed as to what exactly PIPA is and what the terms and concepts it uses mean. At least some of that ambiguity may be a good thing because it allows for interpretation and flexibility; however, as Horton et al. (2013) point out, fidelity is important in implementing participatory approaches. This raises the question of how much flexibility and ambiguity should be built into PME approaches that engage with complexity.

\section{ACKNOWLEDGMENT}

The authors gratefully acknowledge the support of core donors of ICIMOD: the governments of Afghanistan, Australia, Austria, Bangladesh, Bhutan, China, India, Myanmar, Nepal, Norway, Pakistan, Switzerland, and the United Kingdom.

\section{NOTES}

1. Formerly known as the Consultative Group on International Agricultural Research, www.cgiar.org.

2. Association of International Research Centers in Agriculture. 
3. An example of middle range theory is Stachowiak's (2013) global theories of change derived from political science and sociology to describe how policy change happens.

4. Bradbury defines action research as bringing together action and reflection, theory and practice to solve issues of concern in a way that is pragmatic involving the co-creation of knowing with people not about them.

5. The second author was the head of the Strategic Planning and M\&E (SPM\&E) unit during this period. The third author was employed to work as an Impact, Monitoring and Evaluation specialist in 2013.

6. Breaking the spiral of unsustainability in arid and semi-arid areas in Latin America using an ecosystems approach for co-innovation of farm livelihoods.

\section{REFERENCES}

Alvarez, S., Douthwaite, B., Thiele, G., Mackay, R., Córdoba, D., \& Tehelen, K. (2010). Participatory Impact Pathways Analysis: A practical method for project planning and evaluation. Development in Practice, 20(8), 946-958. https://doi.org/10.1080/09 614524.2010 .513723

Bickman, L. (1987). The functions of program theory. New Directions for Program Evaluation, 1987(33), 5-18. https://doi.org/10.1002/ev.1443

Blundo Canto, G., Barret, D., Faure, G., Hainzelin, E., Monier, C., \& Triomphe, B. (2018). ImpresS ex ante: An approach for building ex ante impact pathways. Montpellier, France: CIRAD.

Bradbury, H. (2015). The Sage handbook of action research (3rd ed.). Thousand Oaks, CA: Sage.

Collier, D. (2011). Understanding process tracing. PS: Political Science \& Politics, 44(4), 823-830. https://doi.org/10.1017/s1049096511001429

Davies, R., \& Dart, J. (2005). The "Most Significant Change" (MSC) technique: A guide to its use. Davies-Dart [self-published].

Dhillon, L., \& Vaca, S. (2018). Refining theories of change. Journal of MultiDisciplinary Evaluation, 14(30), 64-87.

Douthwaite, B., Alvarez, S., Cook, S., Davies, R., George, P., Howell, J., ... Rubiano, J. (2007). Participatory impact pathways analysis: A practical application of program theory in research-for-development. Canadian Journal of Program Evaluation, 22(2), 127.

Douthwaite, B., Alvarez, S., Keatinge, J. D. H., Mackay, R., Thiele, G., \& Watts, J. (2009). Participatory Impact Pathways Analysis (PIPA) and research priority assessment. In D. A. Raitzer \& G. W. Norton (Eds.), Prioritizing agricultural research for development: Experiences and lessons (pp. 8-24). Wallingford, England: CABI.

Douthwaite, B., Alvarez, S., Thiele, G., \& Mackay, R. (2008). Participatory Impact Pathways Analysis: A practical method for project planning and evaluation. ILAC Brief 17. Retrieved from https://cgspace.cgiar.org/handle/10568/70093

Douthwaite, B., Apgar, J. M., Schwarz, A.-M., Attwood, S., Senaratna Sellamuttu, S., \& Clayton, T. (2017). A new professionalism for agricultural research for development. International Journal of Agricultural Sustainability, 15(3), 238-252. https://doi. org/10.1080/14735903.2017.1314754 
Douthwaite, B., Kuby, T., Van De Fliert, E., \& Schulz, S. (2003). Impact pathway evaluation: An approach for achieving and attributing impact in complex systems. Agricultural Systems, 78(2), 243-265. https://doi.org/10.1016/s0308-521x(03)00128-8

Ely, A., \& Oxley, N. (2014). STEPS centre research: Our approach to impact. STEPS Centre Working Paper 60. Brighton, England: STEPS Centre. Retrieved from https://stepscentre.org/wp-content/uploads/Impact.pdf

Gallagher, R., \& Appenzeller, T. (1999). Beyond reductionism. Science, 284(5411), 79. https://doi.org/10.1126/science.284.5411.79

Goldstein, J. (1999). Emergence as a construct: History and issues. Emergence, 1(1), 49-72. https://doi.org/10.1207/s15327000em0101_4

Horton, D., Rotondo, E., Ybarnegaray, R. P., Hareau, G., Devaux, A., \& Thiele, G. (2013). Lapses, infidelities, and creative adaptations: Lessons from evaluation of a participatory market development approach in the Andes. Evaluation and Program Planning, 39, 28-41. https://doi.org/10.1016/j.evalprogplan.2013.03.002. Medline:23619235

ICIMOD. (2017). MTAP-IV medium-term action plan 2018-2022. Kathmandu, Nepal: Author. Retrieved from https://upload.openaid.se/document/thailand/icimod-mtapiv-31-august-2017-final.pdf

Lilja, N., Kristjanson, P., \& Watts, J. (2010). Rethinking impact: Understanding the complexity of poverty and change-Overview. Development in Practice, 20(8), 917-932. https://doi.org/10.1080/09614524.2010.513721

Mayne, J. (2015). Useful theory of change models. Canadian Journal of Program Evaluation, 30(2). https://doi.org/10.3138/cjpe.30.2.142

Patton, M. Q. (2010). Developmental evaluation: Applying complexity concepts to enhance innovation and use. New York, NY: Guilford Press.

Pawson, R. (2013). The science of evaluation: A realist manifesto. Thousand Oaks, CA: Sage.

Reason, P., \& Torbert, W. (2001). The action turn: Toward a transformational social science. Concepts and Transformation, 6(1), 1-37. https://doi.org/10.1075/cat.6.1.02rea

Renkow, M., \& Byerlee, D. (2010). The impacts of CGIAR research: A review of recent evidence. Food Policy, 35(5), 391-402. https://doi.org/10.1016/j.foodpol.2010.04.006

Schiffer, E., \& Hauck, J. (2010). Net-map: Collecting social network data and facilitating network learning through participatory influence network mapping. Field Methods, 22(3), 231-249. https://doi.org/10.1177/1525822x10374798

Senge, P. (1990). The fifth discipline: The art and science of the learning organization. New York, NY: Currency Doubleday.

Shambu Prasad, C., Hall, A., \& Laxmi, T. (2006). Engaging scientists through institutional histories. ILAC Brief No. 14. Retrieved from https://cgspace.cgiar.org/handle/10568/70132

Snowden, D. (2010). Naturalizing sensemaking. In K. Mosier \& U. Fischer (Eds.), Informed by knowledge: Expert performance in complex situations (pp. 223-234). New York, NY: Psychology Press.

Stachowiak, S. (2013). Pathways for change: 10 theories to inform advocacy and policy change efforts. Center for Evaluation Innovation. Seattle, WA: ORS Impact. 
Stame, N. (2004). Theory-based evaluation and types of complexity. Evaluation, 10(1), 58-76. https://doi.org/10.1177/1356389004043135

Stein, D., \& Valters, C. (2012). Understanding theory of change in international development. JSRP Paper 1. London, England: Justice and Security Research Programme, International Development Department, London School of Economics and Political Science. Retrieved from http://eprints.lse.ac.uk/56359/

Van Vianen, J., Reed, J., \& Sunderland, T. (2015). From global complexity to local reality: Aligning implementation frameworks with Sustainable Development Goals and landscape approaches (Vol. 1). CIFOR Policy Brief No. 1. Bogor, Indonesia: Center for International Forestry Research (CIFOR).

Vogel, I. (2012). Review of the use of "Theory of Change" in international development. UK Department for International Development (DFID). Retrieved from http://www. theoryofchange.org/pdf/DFID_ToC_Review_VogelV7.pdf

Wholey, J. S. (1987). Evaluability assessment: Developing program theory. New Directions for Program Evaluation, 1987(33), 77-92. https://doi.org/10.1002/ev.1447

Wilson-Grau, R., \& Britt, H. (2012). Outcome harvesting. Cairo, Egypt: Ford Foundation. Retrieved from http://www. Managingforimpact.org/Sites/Default/Files/Resource/ Outome_harvesting_brief_final_2012-05-2-1. Pdf

Yin, R. K. (2013). Case study research: Design and methods. Thousand Oaks, CA: Sage.

\section{AUTHOR INFORMATION}

Boru Douthwaite is an agricultural engineer, technology policy analyst, and evaluator who has 25 years' experience working in the CGIAR System in Africa, Asia, and Latin America. He is currently director and principal researcher of Selkie Consulting Ltd., specializing in theory-driven formative evaluations and support to complexity-aware M\&E systems. Selkie Consulting's clients include MIT, European Commission, World Bank, FAO, UNITAR, IITA, IWMI, CIP, CIRAD, ICIMOD. and IUCN.

Farid Ahmad is a strategic planner, results-based monitoring and evaluation systems developer, and management expert who has more than 20 years' experience working with intergovernmental, international knowledge, and development organizations in the Hindu-Kush Himalayan region. Currently, he is serving as Head of Strategic Planning, Monitoring and Evaluation at ICIMOD. He has demonstrated expertise in participatory program designs, conducting evaluations in complex settings. He has research interest in climate change adaptation, policy, governance, and institutions.

Ghulam-Muhammad Shah works at ICIMOD as Impact, Monitoring and Evaluation Specialist. He has specialized expertise in establishing rigorous evaluation designs in experimental and non-experimental settings, participatory program designs, and conducting evaluations using mixed-method approaches in complex settings. For more than 19 years, he has worked with international, intergovernmental knowledge, and development organizations in countries located in the Hindu-Kush Himalayan region. He has research interests in methodologies and practices used for assessing impacts of social and development programs. 